for a long period. Ferguson and Murray (1971) also reported that lymphocytic infiltration was less in patients with coeliac disease taking a gluten-free diet than in untreated patients.

Our findings together with those of Ferguson and Murray (1971) therefore raise the question of the criteria for diagnosing coeliac disease. Four out of seven of the present patients with a finger and leaf appearance of the mucosa and five of the seven with a leaves only appearance had subnormal serum folate levels. If these patients had not had a rash and had been found incidentally to have low folate levels they might have been labelled nutritional folate deficiency or temperate sprue (Cooke et al., 1963). We suggest that some patients with folate deficiency and a normal macroscopic appearance of the small intestine may have a mild form of coeliac disease.

We are grateful to Mr. J. O. Morgan for carrying out the assays of serum and red cell folate levels. L. Fry and P. P. Seah gratefully acknowledge grants from the Medical Research Council and the Wellcome Trust.

\section{References}

Booth, C. C., Stewart, J. S., Holmes, R., and Brackenbury, W. (1962). In Ciba Foundation Study Group, No. 14. London, Churchill.
Cooke, W. T., Fone, D. J., Cox, E. V., Meynell, M. J., and Gaddie, R. (1963). Gut, 4, 292.

Crabbe, P. A. (1967). Signification du Tissu Lymphoide de Muqueses Digestives, p. 52. Brussels, Editions Arscia.

Douglas, A. P., Crabbe, P. A., and Hobbs, J. R. (1969). Gut, 10, 413.

Ferguson, A., and Murray, D. (1971). Gut, 12, 988.

Fraser, N. G., Murray, D., and Alexander, J. O. D. (1967). British fournal of Dermatology, 76, 509.

Fry, L., Keir, P., McMinn, R. M. H., Cowan, J. D., and Hoffbrand, A. V. (1967). Lancet, 2, 729.

Fry, L., McMinn, R. M. H., Cowan, J. D., and Hoffbrand, A. V. (1968). Lancet, 1, 557 .

Fry, L., McMinn, R. M. H., Cowan, J. D., Hoffbrand, A. V. (1969). Archives of Dermatology, 100, 129

Archives of Dermatology, 100, 129.
Hobbs, J. R., and Hepner, G. W. (1966). Gut, 7, 711.

Hobbs, J. R., and Hepner, G. W. (1966). Gut, 7, 711.
Hoff brand, A. V., Newcombe, B. F. A., and Mollin, D. L. (1966). fournal of Clinical Pathology, 19, 17 .

Marks, J., Shuster, S., and Watson, A. J. (1966). Lancet, 2, 1280.

Marks, R., and Whittle, M. W. (1969). British Medical fournal, 2, 772.

Marks, R., Whittle, M. W., Beard, R. J., Robertson, W. B., and Gold, S. C. (1968). British Medical fournal, 1, 552.

Rubin, C. E., Brandborg, L. L., Phelps, P. C., and Taylor, H. C. (1960). Gastroenterology, 38, 28.

Seah, P. P., Fry, L., Hoffbrand, A. V., and Holborow, E. J. (1971a). Lancet, $1,834$.

Seah, P. P., Fry, L., Rossiter, M. A., Hoffbrand, A. V., and Holborow, E. J. (1971b). Lancet, 2, 681.

Seah, P. P., et al. (1972). Lancet, 1, 611

Shiner, M., and Drury, R. A. B. (1962). American fournal of Digestive Diseases, 7, 744 .

Shuster, S., Watson, A. J., and Marks, J. (1968). Lancet, 1, 1101.

Soltoft, J. (1970). Clinical and Experimental Immunology, 6, 413.

Waters, A. H., and Mollin, D. L. (1961). Fournal of Clinical Pathology, 14, 335.

\title{
Carcinoma of Large Bowel in the Young
}

\author{
ARTHUR VAN LANGENBERG， G. B. ONG
}

British Medical fournal, 1972, 3, 374-376

\section{Summary}

The incidence of large-bowel carcinoma in young people seems to be increasing. Twenty-one cases occurring between the ages of 13 and 25 are reviewed. Most cases were found to be in an advanced state of the disease. High grade malignant growths were found to be twice as common in the young as in adults. The mode of presentation is no different from that in adults and a plea is made for improving results of treatment by earlier diagnosis, which can be established by an increased awareness of the disease in children and young adults.

\section{Introduction}

Cancer of the large bowel is one of the most frequent malignant diseases in the adult, with its peak incidence in the sixth decade. Fortunately it is also one of the more favourable forms of malignancy in terms of operability and long-term survival. In children it is uncommon, but its occurrence in the young has generated much interest, especially with regard to its unfavourable prognosis.

The youngest patient was recorded by Ahfeld (1880), who reported a case in a premature infant. Since then many reports have been made (Sessions and Riddel, 1961; Recio and Bussey, 1965; O'Brien, 1967; Rosato et al., 1969). It has also been noted that there is an increased incidence in young adult life as well as in childhood. Ehrlich and Hunter (1947) examined 813

University of Hong Kong, Queen Mary Hospital, Hong Kong ARTHUR VAN LANGENBERG, M.B., F.R.C.s., Lecturer in Surgery G. B. ONG, F.R.C.s., Professor of Surgery tumours occurring in young men of military age and found no fewer than 342 cancers of the colon and rectum. In St. Mark's Hospital, out of 4,430 cases $1 \%$ occurred before the age of 30 (Recio and Bussey, 1965), while in the Vanderbilt Hospital the incidence below the age of 20 was $0.65 \%$ (Sessions et $a l ., 1965)$. In our own practice in the professorial surgical unit we too have encountered an increasing number of tumours, not only in young adults but also in children and adolescents.

\section{Present Series}

Twenty-one cases of large-bowel carcinoma in young patients have been collected since 1961, during which time the total cases in all age groups numbered 582. This represents $4 \%$ of the total number.

Age and Sex.-The average age of the patients in this series was 21.1 years (range 13-25 years). Most of the patients therefore were young adults, whereas in the past interest has been focused mainly on the occurrence of the disease in young children. The average age in our overall series of large-bowel carcinoma patients was 54 years. Among a total of 582 cases of large-bowel cancer there was a slight predominance of females (301) over males (281). Not only was there a reversal of the sex incidence among the young patients but a noticeable preponderance of 15 males to 6 females-a ratio of $2 \cdot 5: 1$ (see Table).

Clinical Features.-Seventeen patients had melaena either in the form of tarry motions or frank blood. The next most common symptom was an alteration of bowel habit (14), followed by abdominal colic (7), presence of a mass (4), and tenesmus (4). In addition, two patients presented with the clinical picture of acute appendicitis. The duration of symptoms ranged from two days to 18 months, with an average of three months. The corresponding figure for our overall group of patients was four months. 
Clinical Data on Twenty-one Cases of Large-bowel Carcinoma Occurring in the Young

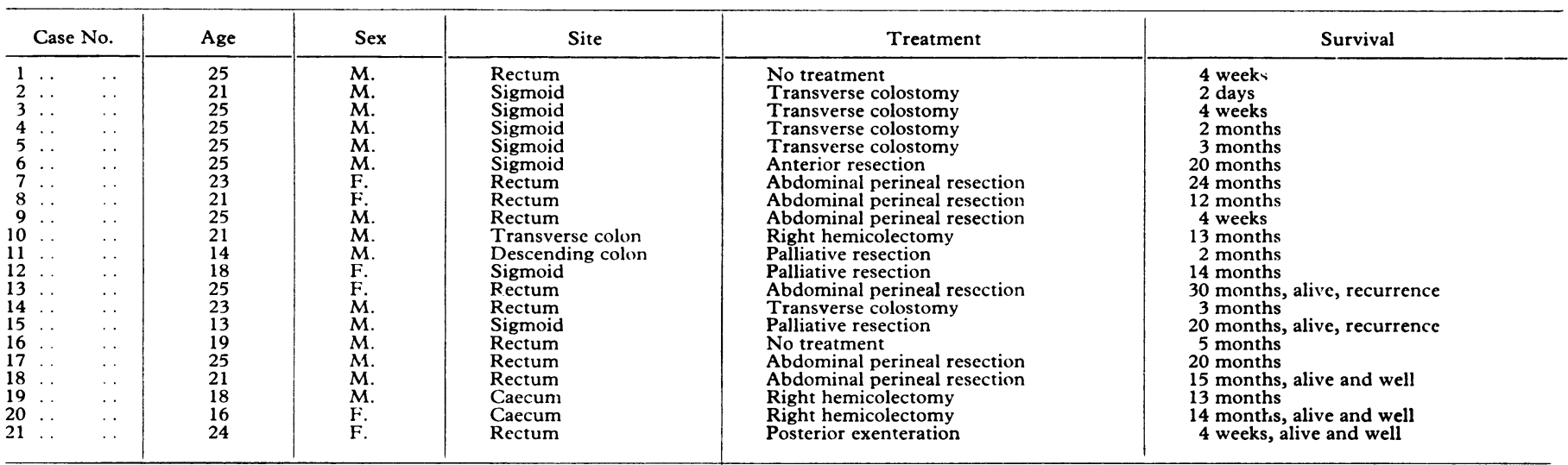

\section{CASE REPORT}

A 16-year-old schoolgirl was admitted to hospital two days after the onset of pain in the right lower quadrant of the abdomen. She also complained of nausea but there was no vomiting. No change in bowel habit was noted. On admission she had a temperature of $101 \cdot 2^{\circ} \mathrm{F}\left(38.5^{\circ} \mathrm{C}\right)$ and there was localized pain and guarding in the right lower quadrant. Rebound tenderness was also present. She was operated on through a grid-iron incision and an inflamed appendix was removed. No other abnormality was noted at the time. The appendix was sent for routine pathological examination and was reported to contain adenocarcinoma in its base. Five weeks later a right hemicolectomy was carried out and a small tumour was found in the caecum. Subsequently on direct questioning she disclosed that there had been four episodes of tarry stool in the month before admission. She had also lost $5 \mathrm{lb}(2.3 \mathrm{~kg})$ in weight over that period. The patient was alive and well 14 months after her last operation.

\section{COMMENT}

Had the melaena and loss of weight not been ignored an earlier diagnosis might have been made and appropriate treatment carried out.

\section{STAGING}

Dukes's classification is adopted but for lesions that have already given rise to distant metastases we prefer to refer to them as stage $D$. With this method of staging the present series was composed of 1 stage A, 2 stage $B, 12$ stage $C$, and 6 stage D lesions. Thus the majority of cases were mainly in stages $\mathrm{C}$ and D.

If the poorly differentiated tumours are grouped with the signet ring tumours, both highly malignant, then $43 \%$ of these patients would fall within this category compared with $20 \%$ in our overall series. Dukes (1940) commented on the increased incidence of anaplastic lesions in the young, and more recently Recio and Bussey (1965) noted highly malignant tumours in $54 \%$ of their series of patients aged under 30 compared with $20 \%$ in their overall series.

Premalignant lesions such as familial polyposis coli do not seem to occur in these patients. Ulcerative colitis did not seem to be a predisposing factor although elsewhere it accounted for a small percentage of cancer development in the young (Michener et al., 1961; Whiteside, 1971). We did not detect any definite genetic background in any patient.

\section{TREATMENT}

Surgery of the large bowel has progressed to such an extent that very high rates of resection are possible. Figures well above $90 \%$ are common (Goligher, 1967; Rosi, 1969; Naunton Morgan, 1971). Though not as high, our resectability rate for carcinoma of the colon is $84 \%$. Among these 21 young patients, however, resection was possible in only $14\left(67^{\circ}\right)$. Eleven had surgical treatment with a view to cure while three operations were palliative. These figures are appreciably poorer than those quoted above. Five patients had colostomy and two patients were beyond treatment.

\section{Results}

Nine patients $(43 \%)$ were dead by the end of the first year. There were no five-year survivors and only five were still alive at four weeks (stage C), 14 months (stage A), 15 months (stage B), 20 months (stage C), and 30 months (stage C). The average survival was $10 \cdot 2$ months from the time of admission.

\section{Discussion}

Carcinoma of the large bowel is more malignant in the young than in the adult. The predominance of poorly differentiated and signet ring type of tumour could account for the late stage of the growths when they were first seen. Clinical diagnosis is not difficult as the symptoms and signs are similar to those presenting in adults. There may, however, be a natural reluctance to diagnose carcinoma in a young patient unless one is aware of the fact that the condition is not uncommon. Appendicitis is a major diagnostic pitfall at any age. Though this is well known among adult patients it may be overlooked in the young. Hence the danger is greater because the underlying disease remains unsuspected, as in the case reported above. There were only two cases of carcinoma of the caecum in the present series and it is significant that in both of these patients appendicitis was the diagnosis made not only preoperatively but also at the time of operation. The final diagnosis became clear only on microscopical examination.

Symptoms of appendicitis can also occur in distal lesions of the large bowel. Millar (1970) reported two cases presenting as appendicitis but at operation the appendix was found to be normal in both cases. One patient had cancer in the rectum and the other in the sigmoid colon. This apparent paradox is probably due to partial intestinal obstruction producing increased intracolonic pressure, which distends the thin-walled caecum and hence gives rise to the tenderness. It is important therefore when operating for appendicitis to be aware of the possibility of a carcinoma anywhere in the large bowel. In addition should the appendix itself be found to be normal careful palpation of the colon and rectum must be carried out. Early recognition is the only way to achieve better results. An encouraging report has come from Rosato et al. (1969). In their series of 35 patients 27 had lesions still confined to the bowel. 
Accordingly the resection rate was over $90^{\circ}{ }_{0}$, with $43^{\circ}{ }_{0}$ surviving five or more years.

Despite the age of the patient symptoms and signs should often lead to suspicion of cancer. Endoscopic examination and barium enema should be more frequently used in its detection.

\section{References}

Ahfelı, F. (1880). Archiv für Gynäkologie, 16, 135

Dukes, C. E. (1940). Fournal of Pathology and Bacteriology, 50, 527

Ehrlich, J. C., and Hunter, O. B. (1947). Surgery, Gynecology and Obstetrics with International Abstracts of Surgery, 85, 98.

Goligher, J. C. (1967). In Surgery of the Anus, Rectum and Colon, 2nd edn., p. 555 . London, Baillière, Tindall, and Cassell.
Michener, W. M., Gage, R. P., Sauer, W. G., and Stickler, G. B. (1961). Ner: England fournal of Medicine, 265, 1075.

Millar, D. (1970). Quoted by Pemberton, M. (1970). British fournal of Surgery, 57, 841 .

Naunton Morgan, C. (1971). Fournal of the Royal College of Surgeons of Edinburgh, 16, 71 .

O'Brien, S. E. (1967). Canadian Medical Association fournal, 96, 1217.

Recio, P., and Bussey, H. J. R. (1965). Proceedings of the Royal Socicty of Medicine, 58, 789.

Rosato, F. E., Frazier, T. G., Copeland, E. M., and Miller, I. D. (1969). Surgery, Gynecology and Obstetrics with International Abstracts of Surgery, 129, 29.

Rosi, P. A. (1969). In Diseases of the Colon and Anorectum, ed. R. Turell, 2nd edn., p. 478. Philadelphia, Saunders.

Sessions, R. T., and Riddel, D. J. (1961). American fournal of Surgery, 102, 66.

Sessions, R. T., Riddel, D. J., Kaplan, H. J., and Foster, J. H. (1965) Annals of Surgery, 162, 279.

Whiteside, J. A. (1971). American fournal of Proctology, 22, 367

\title{
Resistance of Haemophilus influenzae to Trimethoprim
}

\author{
J. ROBERT MAY, JUDITH DAVIES
}

British Medical fournal, 1972, 3, 376-377

\section{Summary}

Out of 210 isolates of Haemophilus influenzae obtained from the sputum of 63 patients with chronic respiratory infections $109\left(52^{\prime}\right)$ were resistant to trimethoprimsulphamethoxazole by the disc test. The minimal inhibitory concentrations of trimethoprim for 17 out of 18 strains recorded as resistant were $10 \mathrm{~kg} / \mathrm{ml}$ or higher. Resistant strains were isolated from time to time from 32 $\left(82^{\prime \prime}{ }^{\prime \prime)}\right.$ out of 39 patients known to have been treated with trimethoprim-sulphamethoxazole, compared with only $1\left(12 \cdot 5^{\circ}\right)$ out of 8 patients known not to have been treated with this drug combination. Resistant strains were isolated most frequently from patients who had received long-term treatment. Since sulphamethoxazole penetrates from the blood into the bronchial secretions less readily than does trimethoprim it seems likely that the ratio of the two drugs in the bronchial tree is far from ideal. This may be an important factor in the use of these drugs for chest infections.

\section{Introduction}

The minimal inhibitory concentration (M.I.C.) of trimethoprim for Haemophilus influenzae is usually about $0 \cdot 1-1 \mu \mathrm{g} / \mathrm{ml}$ (Bushby, 1969), but Waterworth (1969) reported the isolation in our laboratory of two strains for which the M.I.C.s were 32 and $16 \mathrm{~kg} / \mathrm{ml}$ respectively. Commenting on this observation, Garrod and O'Grady (1971) remarked: "Such emergence of resistance so relatively early in the drug's therapeutic history must again be taken as a warning that it should not be used for infections which are almost certainly not of bacterial origin, for trivial infections which do not require antibacterial therapy, or for infections which can equally successfully and conveniently be treated with something else." Our experience of the occurrence of trimethoprim-resistant $H$. influenzae during the past four years strongly reinforces the need for this warning. We report here the details of this experience.

\footnotetext{
Department of Bacteriology, Institute of Diseases of the Chest, Brompton Hospital, London S.W.3

. ROBERT MAY, M.D., F.R.C.PATH., Professor

JUDITH DAVIES, B.SC., Research Assistant
}

\section{Material and Methods}

The survey is based on the findings of routine sensitivity tests of 210 isolates of $H$. influenzae cultured from the sputum of 63 patients investigated between June 1968 and February 1972. Forty-five patients were suffering from cystic fibrosis and 18 had other chronic respiratory disorders-namely, chronic bronchitis, asthma, bronchiectasis, or bronchial carcinoma.

Sensitivity Tests. - It is well known that tests of sensitivity of micro-organisms to trimethoprim and sulphonamides can give erroneous results if the medium used for the tests contains large amounts of the end-products of folate metabolism (Bushby, 1969). These "inhibitors" enable the organism to escape the blockade of folate synthesis and thus to grow in the presence of the drugs. In consequence, organisms may appear to be drugresistant when they are, in fact, sensitive. When confronted with an unexpectedly high rate of resistance to these drugs, therefore, it is necessary to scrutinize the possibility of experimental error of this origin. Accordingly we describe below, firstly, our routine test procedure and, secondly, tests carried out to confirm or refute the findings.

Routine Sensitivity Test Procedure.-Routine sensitivity determinations were carried out by the filter-paper disc method, using standard discs (Oxoid) containing $25 \mathrm{~kg}$ of a mixture of trimethoprim (1 part) and sulphamethoxazole (19 parts). Nutrient agar plates (see below) were flooded with six-hour broth cultures of the test strains diluted $1 / 100$. The excess was pipetted off and the plates were dried at $37^{\circ} \mathrm{C}$, the discs applied, and the plates incubated at $37^{\circ} \mathrm{C}$ overnight. Three types of result were observed: (1) complete inhibition of growth around the disc; (2) an "inhibition zone," but containing minute colonies throughout; and (3) normal growth around the disc. A strain was recorded as being drug-resistant if the zone of complete inhibition extended for less than $2 \mathrm{~mm}$ from the edge of the disc. The culture medium used for these tests was based on the meat-digest broth devised by Breach and his colleagues at Westminster Hospital (Baker and Breach, 1967). To this were added $\mathrm{X}$ factor (haemin, B.D.H.) and $\mathrm{V}$ factor (nicotinamide adenine dinucleotide, B.D.H.) to a final concentration of 3 and $0.3 \mathrm{mg} / 100 \mathrm{ml} \mathrm{w} / \mathrm{v}$ respectively. Lysed horse blood, at a final concentration of $0.5^{\circ} \%$, was also added in order to clear the medium of inhibitors of trimethoprim and sulphonamides (Bushby; 1969; Waterworth, 1969).

Confirmatory Tests.-Twenty-four strains were available for repeat tests. These took the form of estimations of the M.I.C.s of trimethoprim on media known to be free from inhibitorsnamely, Diagnostic Sensitivity Test Agar (D.S.T.A., Oxoid) 